1. MBBS, FCPS (Medicine) Assistant Professor of Medicine Liaquat University of Medical and Health Sciences Jamshoro, Sind, Pakistan.

2. MBBS, M.D (Medicine) Associate Professor of Medicine, Isra University Hospital, Hala Road Hyderabad, Sind, Pakistan.

3. M.D (General Medicine Senior Registra LUMHS Jamshoro.

4. MBBS, FCPS (Medicine) Professor of Medicine LUMHS Jamshoro.

5. MBBS, FCPS (Medicine) Associate Professor of Medicine LUMHS Jamshoro.

6. MBBS.

Postgraduate student of Medicine LUMHS Jamshoro.

Correspondence Address: Dr. Mona Humaira MBBS, FCPS (Medicine) Assistant Professor of Medicine Liaquat University of Medical and Health Sciences Jamshoro, Sind, Pakistan.

monaahmed2810@gmail.com

Article received on:

28/12/2015

Accepted for publication: 02/03/2016

Received after proof reading $12 / 04 / 2016$

\section{ISCHEMIC STROKE;}

THIRTYDAYSMORTALITY OF ISCHEMIC STROKE STUDYFORASSESSMENT BY CLINICAL PARAMETERS AT A TERTIARY CARE CENTRE OF HYDERABAD.

Dr. Mona Humaira ${ }^{1}$, Dr. Atif Sitwat Hayat ${ }^{2}$, Dr. Tariq Zaffar Shaikh ${ }^{3}$, Dr. Hanif Ghani ${ }^{4}$, Dr. Shoaib Ansari ${ }^{5}$, Dr. Irum Sikandar ${ }^{6}$

ABSTRACT... Objectives: Stroke is continued to rise in developing countries of the world. Early recognition and prompt treatment of poor prognostic factors would reduce mortality and morbidity. The objective of our study was evaluation of factors affecting prognosis of ischemic stroke patients and to assess thirty days mortality and outcome. Study Design: Crosssectional, prospective study. Setting: Medical wards of Liaquat University Hospital Jamshoro/ Hyderabad. Period: August 2009 to February 2011. Material and Methods: 150 patients was carried out, patients having acute cerebral infarction of either gender, aged equal to or greater than 13 years were included while patients of stroke because of hemorrhage, space occupying lesion and known diabetic were excluded from study. Results: 150 patients were selected, out of them $60 \%$ were male. Age of patients ranged from 13-90 years with median age of 51 years. At the end of one month mortality rate was $10 \%$ in our study. No improvement was found in $16 \%$ patients, partial improvement in $62 \%$ while only $12 \%$ recovered fully. Conclusion: Our study showed high mortality rate in ischemic stroke patients. Males at and after age of 50 years develop ischemic stroke more commonly. Patients of ischemic stroke having fever, dysphagia, urinary incontinence, hyperglycemia and altered level of consciousness showed poor prognosis.

Key words: Ischemic stroke, prognosis, fever, hyperglycemia, altered level of consciousness, urinary incontinence.

Article Citation: Humaira M, Hayat AS, Shaikh TZ, Ghani H, Ansari S, Sikandar I. Ischemic Stroke; Thirty days mortality of ischemic stroke study for assessment by clinical parameters at a Tertiary Care Centre of Hyderabad. Professional Med J 2016;23(4):444-450. DOI: 10.17957/TPMJ/16.3234

\section{INTRODUCTION}

Stroke is frequently found deadly neurological problem. About 15 million persons suffered from stroke yearly globally, one third of sufferers died and other one third become permanently disabled. ${ }^{1}$ It has been observed that incidence of stroke is continuing to rise in developing countries ${ }^{2}$ and further increase is anticipated. ${ }^{3}$ In contrast to this, situation is getting better in western world ${ }^{2}$, South Asian sub-continent contributes $40 \%$ of mortality of stroke which is equal to that of coronary artery disease. South East Asian people suffered from both these diseases ten years earlier as compared to western people. In spite of great burden of stroke in Pakistan its incidence is not exactly known but estimated incidence is 350,000 new cases every year. ${ }^{4}$
Stroke is a great mental, physical and psychological burden for patients, families and societies. ${ }^{3,4}$ Various clinical or neuroimaging parameters are helpful for assessment of stroke prognosis ${ }^{3}$, their recognition is necessary for treatment and secondary prevention of stroke. In the era of t-PA decision to give antithrombotic or not, depends on assessment of poor prognostic factors. ${ }^{4}$

Different studies have been conducted to see outcome after ischemic stroke worldwide but only a few studies are available from Pakistan, that's why the authors choose this topic.

With neuroimagical advances many scoring system for evaluation of prognosis of stroke has been developed. They include NIHSS (National Institute of Health stroke scale), mRS (modified 
Rankin Scale), Barthel Index, BASIS, Clot Burden Score etc. ${ }^{5}$ Nevertheless each one of these has its own limitation. In this study we used model which was used by the WangY1 and colleagues for assessment of stroke mortality at 30 days ${ }^{6}$ and used their study parameter for assessment of our patient's outcome.

In this era of high technology we have chosen old fashioned clinical parameters in present study, with consideration that majority of our population resides in rural areas where health facilities are scarce. Even in tertiary care hospitals CT scan and MRI facilities are not easily available. This study would help not only in early recognition of outcome of stroke but also in betterment of patients by early management of bad modifiable factors which would reduce the mortality and morbidity. The objective of our study was evaluation of factors affecting prognosis of ischemic stroke patients and to assess thirty days mortality and outcome.

\section{MATERIALS AND METHODS}

This Cross sectional prospective study was conducted in the Medical Wards of Liaquat University Hospital Jamshoro/Hyderabad from August 2009 to February 2011 over 150 patients. Sample was collected through non-probability sampling technique. Patients of acute cerebral infarction of either gender, aged equal to or greater than 13 years were included while patients of stroke because of hemorrhage, space occupying lesion and known diabetic were excluded from the study.

\section{DATA COLLECTION PROCEDURE}

After administrative permission and approval from institutional Ethics Committee, patients fulfilling inclusion criteria were enrolled. After informed consent demography and data regarding patient presenting complaints and risk factors were enquired. Prognostic factors like fever, dysphagia, urinary incontinence, hyperglycemia and level of consciousness were assessed. Blood sugar levels and lipid profile were checked along with ECG. CT scan brain was performed in each and every patient. All this data was recorded on a pre- designed proforma. Control group of 150 patients of ischemic stroke without above mentioned five poor factors were also selected.

\section{DATA ANALYSIS PROCEDURE}

The data was entered and analyze into Statistical packages for social science (SPSS version 17.0). We divided the patients into P1 and P2. Score was given as follow. Impaired consciousness (5 points), dysphagia (3 points), urinary incontinence (4 points), admission body temperature higher than 36.5 degrees $C$ (2 points), and hyperglycemia without a clinical history of diabetes (2 points). P1 group included patients who scored less than 11, group P2 scored equal to or greater than 11 . These results were compared with control group. Test of significance and Chi-square test were applied.

\section{RESULTS}

Total 150 patients were selected. $60 \%$ were male. Age ranged from 13 to 90 years and mean age was 51.63 years. Table-I showed the outcome of the two groups, divided on the basis of score, greater or less than 11. Table-Il showed the two tailed $\mathrm{T}$ Test of significance which proved that both groups are not similar. Table-III showed chi square test result which assessed that there is positive association between outcome and score. Higher the score poor would be the outcome. Table-IV compared the frequencies of outcome in control group and study group. Table-V showed our parameters of prognosis i.e. hyperglycemia, fever, dysphagia, altered level of consciousness and urinary incontinence with outcome. Majority of patients expired belong from 50-65 years of age. In this study regarding risk factors smoking, hypertension, and dyslipidemia were most common in decreasing order of frequency i.e. 33 patients, 30 patients and 14 patients, multiple risk factors were present in 26 patients. Ischemic heart disease, vasculitis, obesity, infections and heart problems (like valvular heart disease and cardiac failure) were found in 12, 8, 9, 9 and 9 patients respectively. 


\begin{tabular}{|c|c|c|c|c|c|}
\hline \multirow{2}{*}{ GROUP } & \multicolumn{4}{|c|}{ OUTCOME } & \multirow{2}{*}{ Total } \\
\hline & EXPIRED & NOT IMPROVED & PARTIAL IMPROVEMENT & FULL IMPROVEMENT & \\
\hline P1 $($ Score $<11)$ & 3 & 0 & 56 & 18 & 77 \\
\hline P2 (Score >11) & 12 & 24 & 37 & 0 & 73 \\
\hline Total & 15 & 24 & 93 & 18 & 150 \\
\hline
\end{tabular}

Table-I.

\begin{tabular}{|c|c|c|c|c|c|}
\hline & \multicolumn{7}{|c|}{ INDEPENDENT T TEST } \\
\hline Equal variances assumed & T & Df & Sig. (2-tailed) & Mean Difference & Std. Error Difference \\
\hline Yes & 22.236 & 148.000 & .000 & 7.29336 & .32799 \\
\hline No & 22.371 & 143.701 & .000 & 7.29336 & .32602 \\
\hline \multicolumn{7}{|c|}{ Table-II. } \\
\hline
\end{tabular}

\begin{tabular}{|c|c|c|c|}
\hline \multicolumn{4}{|c|}{ Chi-Square Tests } \\
\hline & Value & Df & Asymp. Sig. (2-sided) \\
\hline Pearson Chi-Square & $135.233^{a}$ & 30 & .000 \\
\hline $\mathrm{N}$ of Valid Cases & 150 & & \\
\hline
\end{tabular}

\begin{tabular}{c|c|c|c|c|c|}
\hline \multirow{2}{*}{ GROUP } & \multicolumn{5}{|c|}{ OUTCOME (Frequency) } \\
\hline CONTROL & EXPIRED & NOT IMPROVED & PARTIAL IMPROVEMENT & FULL IMPROVEMENT & Total \\
\hline STUDY & 4 & 34 & 81 & 31 & 150 \\
\hline
\end{tabular}

\begin{tabular}{|c|c|c|c|c|c|}
\hline \multirow{2}{*}{ GROUP } & \multicolumn{9}{|c|}{ OUTCOME (Percentage) } & Total \\
\hline CONTROL & EXPIRED & NOT IMPROVED & PARTIAL IMPROVEMENT & FULL IMPROVEMENT & . \\
\hline STUDY & $2.7 \%$ & $22.7 \%$ & $54.0 \%$ & $20.7 \%$ & $100 \%$ \\
\hline
\end{tabular}

\begin{tabular}{|c|c|c|c|c|c|c|}
\hline \multirow{2}{*}{\multicolumn{2}{|c|}{ PROGNOSTIC FACTOR }} & \multicolumn{4}{|c|}{ OUTCOME } & \multirow{3}{*}{$\begin{array}{c}\text { TOTAL } \\
96\end{array}$} \\
\hline & & \multirow{2}{*}{$\begin{array}{c}\text { EXPIRED } \\
12\end{array}$} & \multirow{2}{*}{$\begin{array}{c}\text { NOT } \\
\text { IMPROVE } \\
24\end{array}$} & \multirow{2}{*}{$\begin{array}{c}\text { PARTIALLY } \\
\text { IMPROVE } \\
54\end{array}$} & \multirow{2}{*}{$\begin{array}{c}\text { FULLY } \\
\text { IMPROVE } \\
6\end{array}$} & \\
\hline & PRESENT & & & & & \\
\hline INCONIINENCE & ABSENT & 3 & 0 & 39 & 12 & 54 \\
\hline \multirow{2}{*}{ CONSCIOUSNESS } & ALTERED & 12 & 24 & 67 & 0 & 103 \\
\hline & INTACT & 3 & 0 & 26 & 18 & 47 \\
\hline \multirow{2}{*}{ DYSPHAGIA } & PRESENT & 9 & 18 & 18 & 6 & 51 \\
\hline & ABSENT & 6 & 6 & 75 & 12 & 99 \\
\hline \multirow{2}{*}{ FEVER } & PRESENT & 9 & 18 & 54 & 0 & 81 \\
\hline & ABSENT & 6 & 6 & 39 & 18 & 69 \\
\hline \multirow{2}{*}{ HYPERGLYCEMIA } & PRESENT & 9 & 3 & 21 & 9 & 42 \\
\hline & ABSENT & 6 & 21 & 72 & 9 & 108 \\
\hline \multicolumn{2}{|c|}{ TOTAL } & 15 & 24 & 93 & 18 & 150 \\
\hline \multicolumn{6}{|c|}{ Table-V. } & \\
\hline
\end{tabular}




\section{DISCUSSION}

According to WHO, stroke would be second top most cause of fatality all over World by year $2020 .{ }^{1}$ Major burden of disease is shouldered by South Asia. ${ }^{4}$ Most of studies revealed that $31-40 \%$ cases of stroke occur due to cerebral hemorrhage, and $60-90 \%$ due to ischemia in this subcontinent. ${ }^{7}$

In our study there were 90 males and 60 females. Majority of patients were $50-60$ years of age. In a prospective study conducted in India on acute middle cerebral artery infarction patients for assessment of prognosis, mean age was close to our patients mean age. Male predominance was also similar with $62 \%$ in their study while $60 \%$ in our study. ${ }^{7}$ our patients mean age (51.63) is younger than the western world. In a trial consisting 3020 patients of lacunar infarction, mean age was 63 years. ${ }^{8}$ As age increases chances of full recovery from stroke decrease and patient are more prone for worst outcome irrespective of sex..$^{9,10}$ Regarding age related outcome in our study, mortality was high at or above age of 60 years. Researchers observed that predictors of mortality are different in males and females. In males recurrent stroke and diabetes leads to poor outcome while in females higher age and atrial fibrillation are associated with poorer outcome. ${ }^{11}$

Mortality rates of stroke range from $11-30 \%{ }^{3}$ In our study $10 \%$ of patients expired. This is in comparison of other studies which found mortality rate between $7 \%$ and $32 \%$ in Pakistan. ${ }^{4}$ An international study results released by the CDC showed that from 1995 to 2002, the 30-day mortality rate depend on age, ranged from $9 \%$ to23\% and highest in patients greater than 85 years of age..$^{12}$ In a study conducted in United Kingdom, included people of different ethnicity South Asians patients of ischemic stroke showed poorer outcome. ${ }^{13}$

In a prospective study of 281 patients of stroke, authors found that at the end of one month, mortality rate was $13.5 \%$, almost complete recovery was observed in $22.27 \%$ and poor outcome in $77.72 \%{ }^{14}$

\section{PROGNOSTIC FACTORS}

In the study by Wang $\mathrm{Y} 1$ et al based on five parameters ${ }^{6}$, the authors assigned score to patients and divide them into two groups. The clinical signs and symptoms on which they assigned the score to patients were fever, hyperglycemia, urinary incontinence, dysphagia and level of consciousness. In this study we also followed these parameter and they are discussed below.

It has been observed that body temperature is directly related with the stroke outcome, many studies showed that hyperthermia is itself an independent factor for stroke outcome. As hyperpyrexia leads to the increased metabolic demands of body, this phenomenon causes more damage in penumbra and enhances the infarction. ${ }^{15} \mathrm{~A}$ reduction of 2 to $3^{\circ} \mathrm{C}$ improves the ability of patient to tolerate hypoxia by 25 to 30 percent. ${ }^{16}$ This hypothermia helps to reduce infarct size. Research showed that whatever the cause of increased temperature it results in worst outcome..$^{17}$ In a large study conducted on more than 5000 patients, authors noted that during the first week as late fever occurred poorer would be the outcome. It is recommended that stroke patient should be kept afebrile. ${ }^{18}$ In this study out of a total 15 expired patients nine patients were febrile and, interestingly, all patients who were fully improved did not have fever.

Dysphagia occurs because of neurological involvement of concerned areas of brain. $13 \%-94 \%$ of patients of stroke suffered from dysphagia. ${ }^{19}$ In our study $34 \%$ of patients were found to have difficulty in swallowing. It's presence is a marker of poor outcome. Dysphagia not only related with nutritional problems but increased risk of aspiration pneumonia as well. ${ }^{19}$ Dysphagia occur in almost half of stroke patients but most of them recovered completely by 30 days. Majority of available literature was retrospective analysis of hospital records and showed that major problem associated with dysphagia is aspiration pneumonia. ${ }^{20}$ In our study out of fifteen expired patients nine patients were suffering from dysphagia. 
In the study by this author $28 \%$ of patients were hyperglycemic and out of them $6 \%$ had expired. Nedeltchev et al noted in their study that various factors responsible for 30 days outcome worse in ischemic stroke patients, hyperglycemia in non-diabetic patients lead to poorer outcome. ${ }^{21}$ In a retrospective analysis of 90 ischemic stroke patients, researchers showed that prevalence of hyperglycemia in these patients varied between $31 \%$ down to $6 \%$. It was matched with other studies in which prevalence was $12-53 \% .^{22}$ Post stroke mortality significantly related with hyperglycemia even in non-diabetic. Cause of hyperglycemia in non-diabetic is either stress induced hyperglycemia or undetected diabetes. Different physiological responses may play role in hyperglycemia including increased gluconeogenesis, decrease glycogenlysis and peripheral insulin resistance responses. ${ }^{21}$ In a study conducted in Saudi Arabia, authors found that outcome of patients having hyperglycemia without preceding history of diabetes was worse than patients who were diagnosed case of hyperglycemia. $^{22}$

Different studies showed importance of predictive value of consciousness level. ${ }^{20}$ In a study assessing 14 days mortality Rathor et al found that level of consciousness at time of admission reflect stroke severity. It is an independent factor for assessment of acute mortality. In his study low GCS was strongly related with poor outcome. ${ }^{23}$ In our study $68.6 \%$ patients were found to have altered level of consciousness. Out of them 12 patients expired.

In a study conducted by Muscari in Italy, authors selected 221 patients with ischemic stroke who did not receive thrombolysis and prognosis was assessed after nine months. They found that urinary catheterization or urinary incontinence, oxygen requirement, and persistence of upper limb paralysis, old age along with severe stroke are factors responsible for worse prognosis. ${ }^{24}$ In another study authors found, although urinary incontinence occur in small number of patients, in their study i.e. in only $6.7 \%$ death hazard increased by $45 \% .{ }^{25}$ In our study $64 \%$ patients were suffered from urinary incontinence.

In this study we also assessed risk factors for stroke. Most common risk factor was hypertension in our study. $56 \%$ patients were found to suffer from hypertension. Out of them $26 \%$ patients suffered from one or two more risk factors like IHD, obesity or cigarette smoking. For development of lacunar infarction hypertension is the single most important risk factor. ${ }^{8}$

Hypertension is a modifiable risk factor; its prevalence is very high in Pakistan but neglect from patient and physician side and irresponsible behavior of society and media make the problem worse. ${ }^{3}$ Another study of Basharat et al showed that hypertension was most important potential risk factors for stroke in all age groups while dyslipidemia along hypertension is major contributor for stroke in 25-55 age group. ${ }^{7}$

Although diabetes is another strong risk factor for stroke but we excluded the patients who were diagnosed case of diabetes to verify role of post stroke hyperglycemia on stroke outcome.

In this study, $22 \%$ of patients were found to suffer from stroke with no other risk factor than smoking. Cigarette smoking is now defined as "smoking of at least one cigarette/tobacco per day for preceding three months or more". ${ }^{23}$ Cigarette smoking is related with worst outcome of stroke. ${ }^{7}$

In their study Bozluolcay et al investigating outcome of ischemic stroke patients found that those patients who had ECG changes also had poor outcome at six months. The mortality rate in patients with ECG changes was $38.9 \%$ whereas it was $15.2 \%$ in those with normal ECG. ${ }^{26}$ In a large retrospective study consisting of 7784 patients, researchers found that older age, atrial fibrillation, other cardiac problem and residence in rural areas were strongly related with poor prognosis of ischemic stroke. Last three factors correlate with high death rates and hazard ratio for death by $29 \%, 47 \%$ and $34 \%$ respectively. ${ }^{10}$

Our study showed that mortality rate was also 
high in those patients who had poor prognostic factors while in control group mortality rate was $3 \%$ only. There were a large number of patients who suffered from disabilities both in selected patients and control group. In our part of the world stroke occur at earlier age, carrying worse prognosis and risk factors like hypertension, dyslipidemia, diabetes and IHD etc. are highly prevalent. This study showed high mortality and morbidity which emphasize need of controlling risk factors and hence education of doctors and masses will be required.

This study showed that simple clinical parameters may be reliably used to assess outcome of stroke. Our patients rate of mortality and prognostic factors are not very different from rest of the world. This simple clinical model is not to replace advance methods. It may have various limitations but for recognition of modifiable poor prognostic factors it is significant.

\section{CONCLUSION}

On conclusion, there is high mortality rate in ischemic stroke patients. Males at and after age of 50 years develop ischemic stroke more commonly. Hypertension, smoking, dyslipidemia, ischemic heart diseases (IHD) and obesity were most prevalent risk factors in decreasing order of frequency. Patients of ischemic stroke having fever, dysphagia, urinary incontinence, hyperglycemia and altered level of consciousness showed poor prognosis.

Copyright(C) 02 March, 2016.

\section{REFRENCES}

1. Masood CT. Hussain M. Rehman A. Saleem Abbasi S. Clinical presentation, risk factors and outcome of stroke at a district level teaching hospital. J Ayub Med Coll Abbottabad 2013;25:1-2.

2. World heart federation. Stroke incidence and mortality rates found to be higher in developing than in developed countries for first TIME. [online] 2010 June 19 last update. Available from :URL: http://www. worldcardiocongress.org.

3. Khealani BA, Hameed B, Mapari UU. Stroke in Pakistan. J Pak Med Assoc. 2008 Jul; 58(7):400-3.

4. Wasay M, Khatri IA, Kaul S. Stroke in South Asian countries. Nature Reviews Neurology 2014; 10:135143.

5. Zhao $\mathrm{Y}$, Zaho M, Li X, Ma X, Zheng Q, Chen $X$ et al. The Predictive Value of the Boston Acute Stroke Imaging Scale (BASIS) in Acute Ischemic Stroke Patients among Chinese Population PLoS One. 2014; 9: e113967.

6. Wang Y1, Lim LL, Levi C, Heller RF, Fischer J. A prognostic index for 30-day mortality after stroke. J Clin Epidemiol. 2001; 54:766-73.

7. Zeeshan Basharat, Sadaf Mumtaz. Farah Rashid. Sanah Rashid. Sumaiya A. Mallam Asghar Diljan et al. Prevalence of risk factors of ischemic stroke in a local Pakistani population, High-density lipoproteins, an emerging risk factor. Neurosciences 2012; 17:357-362.

8. Benavente OR, Coffey CS, Conwit R, Hart RG, McClure LA, Pearce LA et al. Blood-pressure targets in patients with recent lacunar stroke: the SPS3 randomised trial The Lancet 2013; $382: 507-515$.

9. Palm F, Urbanek C, Wolf J. Etiology, risk factors and sex differences in ischemic stroke in the Ludwigshafen stroke study, a population-based stroke registry. Cerebrovascular diseases. 2012; 33:69-75.

10. Andy H Lee, Peter J Somerford, Kelvin K W Yau. Factors influencing survival after stroke in Western Australia. Med J Aust 2003; 179:289-293.

11. Smith WS, English JD, Johnston SC. Cerebrovascular Diseases. In: Longo DL. Fauci AS Kasper DL. Hauser SL. Jameson JL. Loscalzo J. Harrison`s Principles of Internal Medicine. $18^{\text {th }}$ ed. New York: Mac Gra Hills; 2012:3270-3299.

12. Heart Disease and Stroke Statistics- 2014 Update. A Report from the American Heart Association Alan S, Go Mozaffarian D, Roger VL, Benjamin EJ. AHA Statistical Update. Circulation 2014; 128:00-00.

13. Gunarathne A, Patel J V, Potluri R, Gill PS, Hughes EA, Lip GY $\mathrm{H}$ et al. Secular trends in the cardiovascular risk profile and mortality of stroke admissions in an inner city, multiethnic population in the United Kingdom (1997-2005). Journal of Human Hypertension. 2008; 22:18-23.

14. Khan SN, Vohra EA. Evaluating the outcome of stroke: a prospective hospital based study, J Postgrad Med Inst 2006; 20:30-5.

15. Zaremba J. Hyperthermia in ischemic stroke. Med Sci Monit. 2004; 10:48-53.

16. Victor M. Ropper AH. Adams RD. Adams \& Victor's 
Principles of Neurology. Cerebrovascular Diseases. 8th edition. New York: McGraw-Hill. 2013; 660-746.

17. Deb P, Sharma S, Hassan KM. Pathophysiologic mechanisms of acute ischemic stroke: An overview with emphasis on therapeutic significance beyond thrombolysis. Pathophysiology 2010; 17: 197-218.

18. Saini M, Saqqur M, Kamruzzaman A, Lees KR, Shuaib A. Effect of Hyperthermia on Prognosis After Acute Ischemic Stroke. Stroke 2009; 40: 3051-3059.

19. Langdon C, Blacker D. Dysphagia in Stroke: A New Solution. Stroke Research and Treatment. 2010. http://dx.doi.org/10.4061/2010/570403.

20. Nedeltchev K, Renz N, Karamesheva A, Haefeli T, Brekenfeld $\mathrm{C}$, Meiera $\mathrm{N}$ et al. Predictors of early mortality after acute ischemic stroke. Swiss Med Wkly 2010; 140:254-259.

21. Bravata DM, Kim N, Concato J. Brass LM. Hyperglycaemia in patients with acute ischaemic stroke: how often do we screen for undiagnosed diabetes. Q J Med 2003; 96:491-497.
22. Akbar DH, Ahmed MM, AL Ghamdi NN, Hijazi NA, Shaikh ARA. Admission Hyperglycemia is a Poor Prognostic Sign in Both Diabetics and Non-Diabetics. J KAU: Med. Sci. 2005; 12:63-71.

23. Rathore JA, Kango ZA, Mehraj A. Predictors of mortality after acute stroke a prospective hospital based study. j ayub med coll abbottabad 2011;23:144146.

24. Muscari A, Puddu GM, N Santoro N, Zoli M. A simple scoring system for outcome prediction of ischemic stroke. Acta Neurologica Scandinavica 2011; 124:334342.

25. Maha K, Ghaffar A, Eleya RZ, Nassef M. Detection of acute small amount of subarachnoid hemorrhage:Comparison between fluid-attenuated inversion recovery MR imaging and CT. J. ejrnm. 2014; 45: 833-839.

26. Bozluolcay M, Ince B, Celik $Y$, Harmanci H, llerigelen $B$, Pelin $Z$ et al. Electrocardiographic findings and prognosis in ischemic stroke. Neurol India. $2003 \mathrm{Dec}$; 51:500-2.

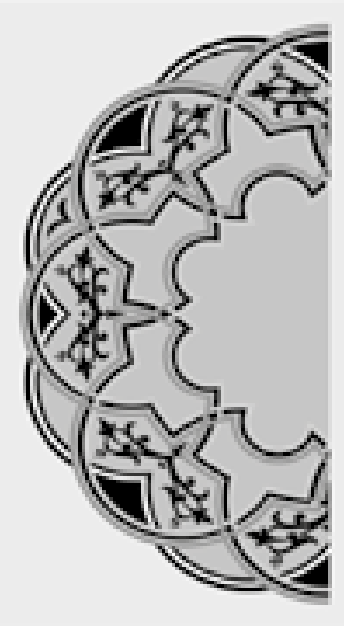

\section{"If it doesn't challenge you, it won't change you."}

Unknown

AUTHORSHIP AND CONTRIBUTION DECLARATION

\begin{tabular}{|c|l|}
\hline Sr. \# & \multicolumn{1}{|c}{ Author-s Full Nam } \\
\hline 1 & Dr. Mona Humaira \\
2 & Dr. Atif Sitwat Hayat \\
3 & Dr. Tariq Zaffar Shaikh \\
4 & Dr. Hanif Ghani \\
5 & Dr. Shoaib Ansari \\
6 & Dr. Irum Sikandar \\
\hline
\end{tabular}

Contribution to the paper

Author $=\mathbf{s}$ Signature

Manuscript drafting, Study

concept \& design

Critical revision of article

Data collection \&

Manuscript typing

Data arranging and

supervision

Statistical analysis of data

Data collection

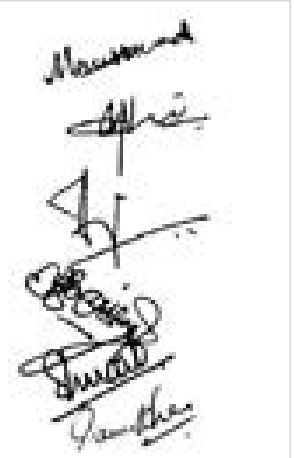

